\title{
O lugar da experiência, da cultura e da aprendizagem multimídia na formação de professores
}

\begin{abstract}
Monica Fantin*
\section{Resumo}

Quais os desafios da formação de crianças, jovens e professores hoje? Falar de saberes e competências necessárias para o professor atuar nos cenários atuais implica perguntar em que medida a universidade, os cursos de licenciatura e os centros de formação docente estão se adequando às novas demandas da educação. Ao situar alguns desafios atuais da formação inicial em relação à cultura digital, o artigo enfatiza a importância da experiência, da formação cultural e da multimídia na formação de professores a partir de uma perspectiva culturalista de mídia-educação. Considerando que a mídia-educação é um campo em construção, a transversalidade e a contribuição multidisciplinar dos saberes das ciências, da educação, da comunicação e das artes constituem um "objeto-fronteira", uma interface que pode interpretar melhor a transformação atual dos conhecimentos e das ferramentas da cultura digital que não se limitam à educação escolar. O texto discute a possibilidade da formação multimídia e suas competências como integração de saberes e contribuições metodológicas provindas de diferentes áreas do conhecimento e da perspectiva das múltiplas linguagens na escola e na cultura. Disso resulta a necessidade de configurar outros espaços para pensar a práxis educativa e formativa e discutir novas formas de mediação cultural nos cenários contemporâneos da formação de professores.
\end{abstract}

Palavras-chave: experiência, formação cultural, aprendizagem multimídia, formação de professores.

\section{The place of experience, culture and multimedia learning in teacher training}

\begin{abstract}
What are the challenges of training children, young people and teachers today? Speaking of knowledge and skills necessary for teachers to perform in current scenarios implies asking to what extent university degree courses and teacher training institutions are adapting to the new demands of education. By highlighting some current challenges of university education, this article emphasizes the importance of experience, cultural training and multimedia in teacher training, from a culturalistic perspective of media education. Considering that media education is a field under construction, the transversality and the contribution of multidisciplinary knowledge of science, education, communication and the arts
\end{abstract}

\footnotetext{
* Professora Doutora da Universidade Federal de Santa Catarina (UFSC), Florianópolis, Santa Catarina, Brasil.
} 


\section{Monica Fantin}

are a "border-object", an interface that can better interpret the current transformation of knowledge and the tools of digital culture which are not limited to school education. The text discusses the possibility of multimedia education and its skills, such as integration of knowledge and methodological contributions deriving from different areas of knowledge and from the perspective of multiple languages in school and culture. From this results the need to set up other spaces for thinking about educational and training praxis, discussing news forms of cultural mediation in contemporary settings of teachers training.

Keywords: experience, cultural background, multimedia learning, teacher training.

\section{Desafios da formação inicial de professores: cultura digital, tecnologias e construção da experiência}

A formação de professores não é um tema simples, e na pesquisa educacional há um enorme acervo de discussão a respeito da formação em geral e da formação inicial em particular. Por vezes, o uso e o tratamento dado ao conceito parecem gerar certo desgaste, o que nos leva a falar em desafio. Entre tantos desafios da formação de professores diante de tantas demandas da sociedade e da desconstrução de certos paradigmas tradicionais, Severino pergunta "como formar o mestre e não simplesmente o instrutor" (2003, p. 16). Para ele, tal desafio remete ao próprio significado da educação, que "não é apenas um processo institucional, seu lado visível, mas fundamentalmente um investimento formativo do humano, seja na particularidade da relação pedagógica pessoal, seja no âmbito da relação social coletiva" (idem). Ao situar as esferas que produzem a existência humana como o universo do trabalho, da sociabilidade e cultura simbólica, o autor destaca a formação integral como uma questão que se coloca para a educação hoje e para as mediações formadoras.

Refletir sobre a formação inicial de professores nos cursos de licenciatura implica pensar o perfil do profissional que se pretende formar e, para tal, há que caracterizar os objetivos que se pretendem alcançar no trabalho desenvolvido com educação de crianças e jovens na sociedade contemporânea. $O$ protagonismo das mídias e a transformação da paisagem comunicativa, cada vez mais marcada pela multimedialidade, têm transformado as relações dos sujeitos entre si e destes com a cultura, modificando as formas de produção, acesso e socialização do conhecimento.

A cultura digital é uma cultura multimídia que usa códigos, linguagens e estratégias de comunicação diferente (RIVOLTELLA, 2008, p. vi). É uma cultura baseada na intermedialidade, na portabilidade e nas mídias pessoais, em que a convergência midiática, as redes sociais, os celulares e outras tecnologias permitem outras formas de interação. Nesse cenário da cultura digital, com a multiplicação dos lugares de saber, crianças e jovens são cada vez mais autores de conteúdos compartilhados em rede, o que redefine a centralidade da 
escola, o papel do professor e das aprendizagens formais e informais. Consequentemente, estas "múltiplas educações" remetem a diversos perfis da figura profissional do professor.

Com a complexidade que envolve tais perfis e papéis profissionais, as identidades docentes serão plurais: professores, pesquisadores, coordenadores, tutores que atuarão em instituições diversas (creches, escolas, centros de educação de jovens e adultos, ONGs, institutos e empresas). Assim, em vez de um perfil específico, poderíamos falar de áreas de competência profissional que podem sugerir diversos perfis que vão sendo delineados a partir das transformações provocadas pelas demandas da sociedade.

Em mapeamento sobre os usos dos meios e os consumos culturais dos professores, Fantin e Rivoltella (2010b, p. 15) sugerem algumas tendências de uso e formas de apropriação das Tecnologias da Informação e Comunicação (TIC) com a elaboração de perfis docentes relacionados aos usos das mídias:

- não usuário - não usa as mídias e as tecnologias porque não sabe ou não teve oportunidade significativa para aprender; não usa as tecnologias porque deliberadamente não quer e "resiste" a aprender;

- iniciante - está começando a usar determinadas tecnologias e o sentido de uso ainda está limitado ao âmbito pessoal;

- praticante - possui um uso consolidado no âmbito pessoal e um uso profissional ainda inicial, limitado a algumas mídias e tecnologias;

- pioneiro-possui um uso pessoal e profissional consolidado e especializado em diversas mídias e tecnologias.

Embora tais perfis não sejam estáveis, dizem respeito ao desenvolvimento de certas competências no âmbito da formação inicial. Relacionado a tais aspectos, a Organização das Nações Unidas para Educação, e Ciência e a Cultura (Unesco) (2008) elaborou um conjunto de publicações sobre os padrões de competência em TIC para professores, e dizem respeito a marco político, diretrizes de implementação e módulos de padrão de competência. Tal proposta articula-se em torno de três abordagens: alfabetização em tecnologia; aprofundamento de conhecimento e criação de conhecimentos. Cada uma dessas abordagens menciona diferentes habilidades decorrentes de seis componentes do sistema educacional mencionados no documento: política, currículo, pedagogia, TIC, organização e desenvolvimento profissional de docentes.

Diversos autores têm pesquisado a questão das competências digitais em ambientes multimídia (RIVOLTELLA, 2005; MIDORO, 2009; FANTIN; RIVOLTELLA, 2010b), sendo possível elaborar uma síntese provisória de algumas competências entendendo-as como desafios da formação de professores: a) analisar o contexto cultural, o ambiente, a estrutura e cultura organizativa da escola; b) conhecer métodos de análise e de pesquisa para viabilizar propostas de uso das TIC na escola; c) conhecer as mídias, suas linguagens e seus 


\section{Monica Fantin}

processos, suas lógicas de produção e consumo; d) atuar pedagogicamente na perspectiva das aprendizagens multimídia e das múltiplas linguagens; e) saber usar e operar com qualidade as mídias e as TIC em contextos formativos; f) analisar textos diversos (escrito, visual, audiovisual, interativo, digital) a partir de diferentes abordagens (alfabética, crítica-reflexiva, ideológica); g) planejar a mediação e a intervenção formativa (planejamento, organização didática, registro e avaliação); i) trabalhar em grupo; j) aprender e ensinar on-line usando crítica e criativamente as ferramentas da cultura digital, as redes sociais e plataformas comunicativas, e outras.

Possuir ou desenvolver competências para trabalhar com as TIC é uma condição fundamental para trabalhar pedagogicamente com as mídias. No entanto, a perspectiva da mídia-educação não se reduz a isso e deve estar aliada à dimensão crítica-reflexiva da formação, como diz Buckingham (2005, p. 4).

Se é quase consenso que os saberes e fazeres listados são necessários à formação dos professores, eles aparecem como desafio, visto que nem sempre estão contemplados na formação inicial. Diante de tal ausência, destacamos a importância de políticas públicas para a formação de professores estarem articuladas às políticas de inserção das TIC nas escolas como condição para transformar o ensino e a formação.

Ao discutir aspectos da formação continuada de professores universitários num contexto das tecnologias digitais, é necessário analisar as transformações que têm ocorrido diante da explosão de oferta dos cursos em educação a distância no país. A esse respeito, Pretto e Riccio (2010) abordam as novas práticas comunicacionais de formação e aprendizagem, desde o sentido da democratização do acesso das tecnologias até a necessidade de políticas públicas para tal. Para eles, os ambientes virtuais de aprendizagem "constituem uma ambiência rica em possibilidade de diálogo com o conhecimento instituído, de construção de novos conhecimentos e culturas e de ampliação de visão de mundo de todos os partícipes desses processos" (p.165). Eles destacam que essa navegação no ciberespaço permite pensar outras direções da formação para a docência on-line, o que remete a uma complexidade que não iremos aprofundar.

Entre continuidades e rupturas, normatização e transgressão, reprodução e criação de certas práticas pedagógicas e da cultura escolar, fica evidente a necessidade de pensar a formação de crianças, jovens e professores numa perspectiva integrada de formação em que educação, cultura, arte, ciência e tecnologia estejam organicamente relacionadas. Diante disso, a pergunta sobre o lugar da experiência, da cultura e da multimídia nessa formação pode ser um ponto de partida para tal reflexão.

Pensar a educação como ação em busca de significação implica perceber a mediação na relação entre sujeito e cultura no sentido de construir 
ações que ampliem o conhecimento de si, do outro e do mundo. Isso possibilita o entendimento das experiências que os sujeitos constroem e de como participam dos sistemas simbólicos da cultura.

Nesse processo, podemos entender o conceito de Vivência (que se refere à vida do indivíduo particular, na sua preciosidade e solidão) em oposição ao de Experiência (que se refere ao vivido, refletido, narrado e compartilhado) a partir de Benjamin (1996), que relaciona o fracasso da Experiência ao fim da arte de contar. Ele reconhece a impossibilidade da experiência tradicional na sociedade moderna e se recusa a contentar-se com a privacidade da experiência individual, a Vivência.

No entanto, a narrativa continua a existir de outras maneiras na sociedade contemporânea, sendo fruto das experiências possíveis nas condições atuais. Afinal, o próprio Benjamin ligou as transformações estéticas do início do século XX que subverteram a produção cultural, artística e política da época, às profundas mutações da percepção (aisthêsis) e das formas de recepção coletiva e individual, sobretudo aquelas provocadas pelo cinema. Assim, as artes podem exercitar novas percepções sensoriais e outras formas de aprendizagem.

Na relação entre arte, comunicação e educação, a multiplicidade de formas que as narrativas assumem na contemporaneidade nos leva a pensar nas diversas linguagens presentes na formação e nas diversas formas pelas quais estruturamos nossa experiência: a experiência dos sentidos através da percepção, a experiência profunda e simbolicamente codificada através da interação com o mundo social, a experiência vicária que alcançamos no ato de leitura, como enuncia Bruner (1998, p. 164).

Daí a importância de entender formação como prática cultural através das múltiplas linguagens na formação docente, uma vez que o que é vivido e percebido com caráter sensível nos atinge mais facilmente. Aliado a isso, a ideia benjaminiana de conhecer sentindo e de sentir conhecendo pode superar a visão cartesiana do conhecimento.

E aqui entra a necessidade de pensar com rigor o conceito de experiência educativa. Para Dewey, não basta exaltar a experiência, é necessário encontrar um conceito adequado, pois é educativa apenas a experiência que favorece a expansão e o enriquecimento da pessoa e isso depende da qualidade da experiência que se tem. "A qualidade de cada experiência tem dois aspectos: de um lado, pode ser imediatamente agradável ou desagradável, de outro, ela exercita a sua influência sobre a experiência posterior" (DEWEY, 2004, p. 12). Se o primeiro aspecto da experiência é fácil de ver, o efeito de uma experiência não se pode conhecer de imediato, o que apresenta um problema à educação baseada na experiência: aquele de escolher o tipo de experiência presente que viverá fecunda e criativamente nas experiências que se seguirão. Disso resulta na importância de pensar o lugar que a experiência ocupa na formação. 


\section{Monica Fantin}

Ao elaborar uma agenda de pesquisa para a formação docente, Zeichner (2009) aponta diversos aspectos sobre as perspectivas de trabalho nesse campo e discute as conexões entre as características do professor, sua formação, suas aprendizagens e suas práticas docentes. Nessa articulação, ele recupera a contribuição de Nóvoa, quando enfatiza que "a formação está indissociavelmente ligada à produção de sentidos sobre as vivências e experiências da vida" (1995, p. 26). E é essa produção de sentido que buscamos destacar ao articular experiência, cultura e multimídia na formação de professores.

\section{A formação cultural e outros espaços de saber}

Entender que a prática educativa não se refere apenas ao trabalho docente mas diz respeito à formação da pessoa em sentido amplo, significa pensar a ética, a estética e outras dimensões da vida. Afinal, se a escola é um centro de formação, espera-se que "atividades ligadas à cultura, como música, literatura, teatro, cinema, entre outras, sejam partes importantes do processo educativo" (UNESCO, 2004,p. 89). Nesse sentido, pensar a formação cultural a partir de tais dimensões sugere aproximar a arte, a estética, as novas mídias no sentido de circunscrever um âmbito disciplinar ainda inédito, diz Granata (2009). Tal aproximação se coloca no interior de um processo histórico assinalado por uma "nova sensibilidade cultural e social que emerge no final do século XX em concomitância com a evolução dos sistemas das mídias, acelerada pela convergência entre tecnologia digital e redes informáticas" (GRANATA, 2009, p. 9).

Ocorre que, ao transitar pela formação cruzando as fronteiras da arte, mídia e pedagogia, é necessário ultrapassar a delimitação de territórios ocorrer a partir das áreas de conhecimentos e reconhecer que "o encontro pode ocorre quando, ciente das especificidades de cada campo, os sujeitos se dispuserem a olhar, a procurar compreender as diferenças e, então, iniciar um diálogo", diz Albano (2010, p. 34).

Na busca desse diálogo, pesquisas sobre os consumos culturais de professores e sobre impasses e desafios da formação docente (UNESCO, 2004; GATTI; BARRETO, 2009) demonstram o quanto a formação cultural deixa a desejar no percurso formativo dos professores. No mapeamento sobre o perfil docente realizado pela Unesco (2004, p. 89-106), as práticas culturais dos professores revelam uma nítida associação entre as formas de consumo e o capital cultural na formação das identidades individuais e sociais, que por sua vez são construídas pelo acesso aos bens econômicos e culturais a partir da condição de classe, gênero, etnia, etc. Se considerarmos que os consumos culturais se relacionam com as práticas midiáticas e tecnológicas, Gatti e Barreto (2009, p.118-152) revelam um dado preocupante na formação inicial: a quase inexistência de disciplinas sobre mídias e tecnologias nos cursos de licenciaturas no país. Elas destacam que, nos cursos de Pedagogia, sua presença se restringe a $0,7 \%$ das disciplinas obrigatórias e $3,2 \%$ das disciplinas optativas. 
Este dado ajuda a entender os consumos midiáticos e culturais dos professores. Em uma investigação desenvolvida a esse respeito em dois contextos socioculturais, Fantin e Rivoltella (2010b, p. 8) destacam que mais de $60 \%$ assistem à TV todos os dias e entre os programas preferidos estão: telejornais, filmes, documentários, programas humorísticos e de opinião. Em relação ao cinema, aparece um uso difuso, e metade dos professores que participaram da referida pesquisa raramente vão ao cinema, e o mesmo ocorre em relação ao museu, teatro e shows musicais. No tempo livre, a preferência dos professores é navegar na Internet, assistir TV, ler revistas/jornais, ouvir música e realizar atividades de estudo e formação.

É provável que a questão financeira e o excesso de trabalho incidem sobre as escolhas indicadas, mas, ao mesmo tempo, altos consumos com vertente tecnológica indicam uma significativa dimensão de acesso tecnológico presente nos ambientes domésticos na amostra investigada. Embora a aquisição de novos hábitos de consumos midiáticos no âmbito doméstico não signifique sua inclusão no âmbito escolar, é possível acreditar que eles podem repercutir positivamente no fazer docente.

Um fenômeno instigante apontado na referida pesquisa é que determinadas práticas culturais em ambientes tecnologizados parecem estar distantes de certas práticas culturais do tempo livre, como ir ao cinema, teatro, etc. E isso pode ser um dado interessante para pensar o caráter instrumental que as experiências assumem e a aparente ausência de um pensamento com dimensões éticas e estéticas mais evidenciadas na formação.

Ao discutir o conceito de formação cultural de professores, Nogueira (2008, p. 2), define-o como "um processo pelo qual o indivíduo se conecta ao mundo da cultura, mundo esse entendido como espaço de diferentes leituras e interpretações da realidade, promovidas pela Arte, nas suas diferentes modalidades, e pela Literatura." Ela articula tal processo com a experiência estética e destaca diversas possibilidades da formação cultural em um curso de Didática Geral, no qual o cinema, a poesia, a fotografia, a música e a pintura foram linguagens e conteúdos abordados. Tal experiência permitiu aos alunos/futuros professores lidarem melhor com a alteridade a partir de diferentes leituras de mundo, enriquecer o repertório a partir de um legado construído ao longo dos séculos, e reinventar a própria dimensão de humanidade, diz a autora.

Considerar a experiência cultural de estudantes de licenciaturas a partir de possíveis formas de participação em espaços da cultura como museus, galerias de arte, cinema, teatro, bibliotecas, espaços de apresentações musicais, etc. pode revelar outra dimensão dos saberes da formação inicial. Para além da construção sistematizada de conhecimentos, a singularidade que tal construção de sentidos propicia diante destes espaços da cultura possibilita não apenas ampliar o repertório cultural como também ampliar o entendimento de sala de aula e provocar certos estranhamentos. Possibilita outras formas de 


\section{Monica Fantin}

ver e sentir os espaços públicos como renúncia ao previsível e construção de outros diálogos e parcerias com a cultura.

Diversos estudiosos acreditam que só a partir da perspectiva da aprendizagem poderemos mudar o ensino. Hoje, sabemos que a aprendizagem está se transformando e se configura como teia de dimensões: afetiva, sensorial, simbólica, estética, formal, não-formal, informal que não está circunscrita ao tempo/espaço escolar. Nesse contexto, a aprendizagem formal possui suas especificidades e é uma das únicas que depende de alguém que ensine e promova as mediações necessárias.

Reconhecer que a aprendizagem escolar é apenas um dos espaços de aprendizagem mais ampla na vida do sujeito é importante para redimensionar essa aprendizagem e legitimar outros tipos de experiências que ocorrem fora dela, pois hoje o saber está em toda parte, "não só no livro, no interior da escola, mas no museu, na biblioteca, no cinema, nos centros culturais, Internet, nos infinitos espaços sociais que nos rodeiam, que nos invadem", destacam Leite, Guimaraes e Nunes (1999, p. 163). Dessa forma, cabe pensar um processo formativo que vislumbre um trabalho diferenciado com a cultura audiovisual, imagética, literária, artística, musical, midiática e digital articulado com as mais diversas formas de participação de crianças e jovens na cultura.

Ao ampliar o espaço da sala de aula para outros espaços de cultura, certos eventos podem ser extensão da sala de aula, onde também é possível aprender em novas paisagens e interagir com outros espaços do lugar e/ou da cidade em busca de outros olhares sobre o cotidiano. Recriar cenários, personagens e enredos diversos de forma presencial ou on-line, com a arte da paródia, da poesia, da música, do canto e da dança é ter a possibilidade de descobrir talentos inesperados e revelar muitos outros escondidos. Da mesma forma, interagir com a imaterialidade e os espaços da cultura digital nas navegações do ciberespaço e nas redes sociais também pode significar a possibilidade de exercer uma cidadania instrumental e de pertencimento para além do "real e virtual" que o ambiente multimídia propicia.

Ao entender os lugares da formação para além do aspecto físico e institucional podemos tomar de empréstimo a noção de espaço de Massey (2008, p. 29), que envolve desde a extensão como superfície de um lugar até um intervalo espacial ou de tempo. Em tal abordagem, o espaço pode ser entendido como produto de inter-relações, como construção através de interações globais e intimamente pequenas, e como possibilidade de multiplicidade.

Pensar a educação com tal entendimento de espaço é trabalhar com possibilidades concretas de acesso à cultura e construção de inter-relações propiciadas por outras formas de mediação. Assim, a formação inicial pode, gradualmente, permitir que professores sensíveis, bem informados e bem preparados possam ter acesso a uma diversidade de conteúdos e linguagens que 
deve ser encorajada. A partir do conhecimento que o professor tem de suas competências e da sensibilidade para com as necessidades dos estudantes é que fará suas escolhas. Dependendo de seus objetivos, poderá transitar tanto pelas obras clássicas, eruditas e populares do currículo, como na cultura híbrida de que fala Canclini (2000); tanto pelas obras da indústria cultural e do consumo da comunicação de massas, como destaca Martín-Barbero (2001) como pelos ambientes da sociedade em redes de que fala Castells (2006). Nessa diversidade não basta falar sobre a "necessidade de experiência", pois depende das qualidades que elas possuem e das mediações possíveis nesse percurso.

Embora a reflexão dessas atividades possua diferentes vertentes de interpretação, neste momento elas sugerem uma metodologia que muda a perspectiva de entender a formação. $E$ isso significa entender a sala de aula como uma possibilidade de encontro pedagógico, pois a aula não seria apenas um lugar, e sim um sistema de relações, uma "comunidade de aprendizagem", como diz Bruner (2002). Segundo o autor, uma das propostas mais radicais da psicologia cultural no campo da educação é a que revoluciona a concepção de sala de aula, "considerando-a uma subcomunidade de pessoas que aprendem uma com a outra, onde o docente tem a tarefa de orquestração" (idem, p. 35). Para ele, esta subcomunidade não diminui o papel nem a autoridade do professor, que tem a tarefa de compartilhar com os outros o seu papel. Em tal perspectiva, a sala de aula amplia-se e pode ser vista como lugar de experiências, de aprendizagens e de cultura.

Mais que ampliar a sala de aula para outros espaços e eventos, a formação cultural significa a possibilidade de apropriação de aspectos da arte, da ciência e da cultura através da produção e expressão com as múltiplas linguagens. Na perspectiva da digital literacy e informational literacy (RIVOLTELLA 2008, p. 217), isso significa a construção de competências de cidadania que oferecem instrumentos conceituais e culturais para criar, compartilhar, selecionar e avaliar de modo adequado as informações disponíveis na cultura digital (RIVOLTELLA, 2010, p. 43). Isso se relaciona com uma formação plural e com a ideia de multiliteracies (HOBBS, 2006, p. 16), entendida como conceito de literacia em todas as formas de expressão e comunicação audiovisual, artística, eletrônica e digital em seus diferentes objetos de estudo e análise.

\section{Aprendizagem multimídia e as múltiplas linguagens na formação de pro- fessores}

Os sentidos culturais das sociedades contemporâneas se organizam cada vez mais a partir das mídias, que, sendo parte da cultura, exercem papel de grandes mediadoras entre os sujeitos e a cultura mais ampla, modificando as formas de interações entre as pessoas. Nesta perspectiva, a dimensão político-cultural da formação deve abordar as grandes mudanças sociais provocadas pelas mídias e tecnologias na economia, ciência, arte, cultura, nos relacionamentos humanos e na formação escolar. 
Entender a mídia como um ambiente em que "os meios de comunicação são indispensáveis para compreender o que nos torna humanos", diz Silverstone (2009, p. 264), implica pensá-la como um importante canal não apenas da representação da realidade histórica como também do processo de desumanização através de imagens e narrativas que assumem papel fundamental na indústria da cultural global.

Ao mesmo tempo em que a estruturação da vida cotidiana está plena de informação, o acesso a ela é altamente fragmentado e vai-se tornando uma característica que determina a qualidade das interações sujeito-informação. $\mathrm{Na}$ medida em que muitos estudantes não possuem um capital cultural para selecionar os estímulos fragmentados e descontínuos provindos da cultura digital, os cursos de formação inicial poderiam contribuir para problematizar tais questões. Isso requer uma reflexão sobre a relação entre as mídias, a comunicação e a educação com as políticas socioeconômicas mais amplas.

Ao sermos educados por imagens, sons e outros meios provindos da cultura digital, as mídias asseguram formas de socialização e transmissão simbólica, mas também participam como elementos importantes da nossa prática sociocultural na construção de significados da nossa inteligibilidade do mundo. Embora as mediações culturais ocorram de qualquer maneira, tal fato necessita de mediações pedagógicas.

O campo da educação-comunicação tem se preocupado com as mediações escolares e tem se configurado como um campo teórico-prático muito fértil. É no contexto de tal interface que aparece a mídia-educação, aqui entendida como possibilidade de educar para/sobre as mídias, com as mídias e através das mídias, a partir de uma abordagem crítica, instrumental e expressivoprodutiva (FANTIN, 2006, p. 85-6). Esta perspectiva de mídia-educação implica a adoção de uma postura "crítica e criadora" de capacidades comunicativas, expressivas e relacionais para avaliar ética e esteticamente o que está sendo oferecido pelas mídias, para interagir significativamente com suas produções, para produzir mídias e também para "educar para a cidadania".

Nesse sentido, uma concepção ecológica de mídia-educação (RIVOLTELLA, 2005; FANTIN, 2006), que significa o uso de todos os meios, dos tradicionais aos contemporâneos, na educação nos leva ao conceito de convergência entre arte, mídia e comunicação (MACHADO, 2007; SANTAELLA, 2005), que, por sua vez, remete aos ambientes multimídia.

Ao destacar o conceito de convergência como fluxo de conteúdos em diversas plataformas de mídia, a cooperação entre mercados midiáticos e o comportamento migratório dos públicos, para Jenkins (2009, p. 29), "convergência é uma palavra que consegue definir transformações tecnológicas, mercadológicas, culturais e sociais, dependendo de quem está falando e do que imaginam estar falando". Ligado ao conceito de convergência dos meios de 
comunicação, ele destaca o de cultura participativa como uma ferramenta necessária para entender a cultura das novas mídias e, consequentemente, a literacia dos novos meios.

Entre as novas competências e habilidades que fazem parte da literacia dos novos meios, Jenkins (2006, p. 4) inclui o jogo, a performance, a simulação, a apropriação, a multitarefa, a cognição distribuída, a inteligência coletiva, a avaliação, a navegação transmidiática, o trabalho em rede e a negociação. Ao detalhar as características de cada habilidade na navegação transmidiática, o autor destaca o conceito de design literacy como uma "competência expressiva básica na era moderna” (KRESS apud JENKINS, 2006, p. 47). Ou seja, a capacidade de expressar ideias através de diferentes sistemas de representação incluindo palavras escritas e faladas, imagens fixas ou em movimento, músicas, $3 D$, etc., seria uma condição de comunicação nos dias de hoje. E isso implica pensar nos ambientes multimídia em que tais processos ocorrem.

Refletir sobre o sentido de acesso, análise (interpretação e reflexão), avaliação e criação de tais formas de expressão nos leva a pensar nas possibilidades de uso das tecnologias e do letramento digital entendido como media literacy e/ou "alfabetização midiática". No entanto, em contextos socioculturais em que nem a leitura e a escrita foram/são apropriadas - sugerindo, em alguns casos, uma passagem da cultura oral para a digital -, o desafio é ainda maior, o que remete à discussão de conceitos a respeito das multiliteracies, entendida como leitura, escrita, compreensão (análise-interpretação-reflexão) e produção de diversos tipos de texto em todas as linguagens: escrita, audiovisual, musical, eletrônica, midiática, digital (FANTIN, 2011) em ambientes de aprendizagem multimídia.

Ao utilizar o termo multimídia para referenciar um ambiente que envolve diversos sistemas simbólicos que acrescentam outros aspectos ao texto impresso da palavra escrita e da imagem estática, destacamos tanto o uso do audiovisual, do cinema e da televisão e das dinâmicas de imagem e som, quanto o espaço do hipertexto e das navegações e interações que a cultura digital propicia. No entanto, na relação entre multimedialidade e interatividade, "televisão, simulação tridimensional, realidade virtual, ambientes de leitura e escrita hipermidiática são ambientes multimídia mais comuns mas constituem também dispositivos para aprendizagens bem diferentes entre si", destaca Calvani (2004, p. 21).

Dessa forma, se as tecnologias cognitivas condicionam cada vez mais nosso modo de pensar, nossa visão de conhecimento e nossa própria identidade, para Calvani (2004, p. 26) "é indispensável buscar novos espaços noéticos" para redefinir as finalidades educativas que orientem o uso formativo de tais tecnologias. Nesse sentido, ele propõe a passagem de uma mídia-educação a uma multimídia educação que faça uso de todo esse ambiente multimidático na perspectiva de uma "ecologia midiática" (idem, p. 55) que busque um equilíbrio e 


\section{Monica Fantin}

evite formas de "desnutrição cognitiva", que para ele implicaria "excessos e obesidade midiática" ou falta e ausência de familiaridade com algumas mídias.

Nesses ambientes e aprendizagens multimídia, as ferramentas da cultura digital estão promovendo um conjunto de transformações nos comportamentos sociais com diversos significados culturais. Fantin e Rivoltella (2010a, p. 90-91) destacam alguns elementos da transformação de certas práticas culturais: a) a perda da centralidade da televisão (consumo cada vez maior de outras práticas e suportes como o computador, a Internet, o celular); b) o consumo torna-se uma atividade complexa e multitarefa (fazer várias coisas ao mesmo tempo); c) a transformação do perfil do usuário (de espectador ao de produtor); d) a necessidade de comunicar e estar sempre conectado (um tempo cada vez mais cheio e intolerância aos vazios do silêncio), etc.

Neste quadro, parte de tais consumos e práticas adentram o cotidiano escolar e interpelam pela produção de novos usos da tecnologia, de novos suportes, conteúdos e, consequentemente, novas (in)formações técnicas para apresentação de tais materiais, que podem estar articulados em uma abordagem (áudio)visual a fim de tornar o processo de aprendizagem mais significativo, sem alterar a complexidade do conhecimento. São aspectos da multimedia learning, que Mayer (2001) aborda na perspectiva da construção de aprendizagem interativa. Ou seja, uma aprendizagem que pressupõe interatividade promove a integração da representação verbal, escrita e audiovisual em diversos suportes tecnológicos - tradicionais, impressos, eletrônicos e digitais -, que, por sua vez, promovem diferentes tipos de aprendizagem.

A ideia da aprendizagem multimídia parte de diversos princípios. Entre eles, Mayer (2001) destaca que se aprende melhor a partir de uma representação visual e verbal do conteúdo (palavras e imagens) e que na interatividade básica a explicação multimídia permite ao usuário controlar o fluxo de palavras e imagens agregando-se ali a possibilidade de explorar um ambiente virtual, manipular diversas variáveis e fazer escolhas para controle da mensagem multimídia e possível transferência de formas e conteúdos para outros contextos de aprendizagem. Assim, o tipo de interatividade construída na aprendizagem multimídia relacionase com as novas práticas de consumos e midiáticas, que por sua vez relacionamse com os diferentes meios e TIC e suas múltiplas linguagens.

Nesse quadro, num movimento entre práticas cotidianas informais e formais, os cursos de formação podem atuar tanto na perspectiva de uma fundamentação teórico-metodológica de tais práticas através de um trabalho reflexivo e mídia-educativo, como na perspectiva de oficinas teórico-práticas a respeito das múltiplas linguagens.

No entanto, a presença e o uso das tecnologias nas práticas educativas precisam estar articulados não só a uma reconfiguração da escola e seus espaços, mas sobretudo a programas de formação inicial e continuada que discutam 
o novo perfil profissional do professor nos cenários atuais, e em sua relação com a cultura, com as mídias e tecnologias, que são conteúdos e ferramentas fundamentais para a educação hoje.

Conhecer as possibilidades de uso pedagógico das TIC é fundamental para uma educação multimídia que articule as dimensões crítica, instrumental e produtiva da mídia-educação às propostas de estudo teórico-práticas a respeito da produção midiática (literária, audiovisual, fotográfica, jornalística, digital) e suas diferentes formas de interação e colaboração em rede. Nesse sentido, propostas de oficinas na formação pode ser uma possibilidade de promover situações que enfatizam a circulação de saberes e a construção de autorias multimídias num percurso de conhecer fazendo, aprender cooperando e educar para as múltiplas linguagens (FANTIN, 2009), tendo como princípios educativos de aprendizagem as dimensões de uso, apropriação, expressão e reflexão.

Para a autora, a ideia de conhecer fazendo pressupõe uma aprendizagem que se constrói através da experiência do fazer individual e coletivo em que o sujeito precisa "fazer para aprender" e ter a possibilidade de refletir sobre o que fez compartilhando a experiência. A ideia de aprender cooperando entende que o trabalho cooperativo não se limita à organização coletiva, às regras de vida em comum e à divisão de responsabilidades, e envolve a oferta de reais possibilidades de trabalho compartilhado e interativo. E a ideia de educar para as múltiplas linguagens significa reconhecer a centralidade da linguagem no processo educativo em toda a sua pluralidade e multiplicidade de expressões (oral, escrita, corporal, plástica, musical, audiovisual, midiática, digital). Isso implica discutir as diversas funções das múltiplas linguagens, entendendo-as também como metaeducação que possibilita o diálogo com outras áreas.

Assim, a possibilidade de estudantes se apropriarem da palavra e das imagens é um processo de aprendizagem multimídia que pode ser ampliado com as múltiplas linguagens nos espaços da formação docente permitindo a construção de outros discursos nas práticas educativas. Tais processos permitem pensar propostas de atuação pedagógica na escola que considere outras formas de fazer, aprender, refletir e representar como momentos fundamentais de um processo de ensino-aprendizagem que pretende articular ciência, arte, comunicação e cultura.

\section{Outros lugares da formação}

Ao perguntar pelo lugar da experiência, da cultura e da aprendizagem multimídia na formação de professores buscamos entender os lugares da formação enfatizando o espaço como produto e processo de interações e inter-relações em ambientes plurais que constroem experiências e conhecimentos. Também enfatizamos o espaço educativo como um ecossistema de relações entre ensino e aprendizagem em que as múltiplas linguagens e aprendizagens multimídia fazem parte dessa relação. 
No processo formativo de conhecimento de si, do outro e do mundo, destacamos a importância da formação cultural dos professores na perspectiva da mídia-educação como condição de experiências diferenciadas no processo de ensinar e aprender nos cursos de formação inicial e como mediação e participação na/da cultura. Nesse percurso, vimos que os desafios da formação relacionados às tecnologias da informação e comunicação podem tornar necessária uma construção da experiência em outros lugares do saber, entendidos como espaço aberto, plural, interativo e relacional que implica pensar o devir de outras práticas formativas.

Nesse devir, o espaço físico e simbólico da formação, os processos e produtos das relações e práticas materiais e imateriais também podem ser entendidos como encontros de narrativas em ambientes multimídia com suas múltiplas linguagens. Encontros e linguagens que promovem aprendizagens, estranhamentos e provocações necessárias para descobrir outros modos de entender o sujeito em seu processo de formação, que também pode ser entendido como construção de saberes e fazeres que se transformam em ferramenta e condição de inteligibilidade de mundo na sociedade contemporânea. E esse lugar parece estar em permanente construção.

\section{Referências}

ALBANO, A. A. Arte e pedagogia: além dos territórios demarcados. Cadernos Cedes, Campinas, v. 30, n. 80, p. 26-39, jan./abr. 2010.

BENJAMIN, W. Obras Escolhidas I: Magia e técnica, arte e política: ensaios sobre a literatura e história da cultura. 7. ed. São Paulo:Brasiliense, 1996.

BRUNER, J. Realidade mental, mundos possíveis. Porto Alegre: Artes Médicas, 1998.

. La cultura dell'educazione. Milano: Feltrinelli, 2002.

BUCKINGHAM, D. Media Education: literacy, learning and contemporany culture. Cambridge: Polity Press, 2005.

CALVANI, A. I nuovi media nella scuola. Roma: Carocci, 2004.

CANCLINI, N. G. Culturas híbridas. 3. ed. São Paulo, Editora da USP, 2000.

CASTELLS, M. A sociedade em rede. 9. ed. São Paulo: Paz e Terra, 2006.

DEWEY, J. Esperienza e educazione. Milano: La Nuova Itália, 2004.

FANTIN, M. Mídia-educação: olhares, conceitos e experiências Brasil e Itália. Florianópolis: Cidade Futura, 2006.

. Formação cultural e mídia-educação na pedagogia. In: Anais VI Congresso Internacional de Educação: Educação e Tecnologia, São Leopoldo: Unisinos, 2009. 
. Beyond Babel: Multiliteracies in Digital Culture. International Journal of Digital Literacy and Digital Competence (IJDLDC), 2(1), 1-6, 2011.

FANTIN, M.; RIVOLTELLA, P. C. Crianças na era digital: desafios da comunicação e da educação. Revista Estudos Universitários, Sorocaba, v. 36, n. 1 p. 89-104, jun. 2010a.

. Interfaces da docência (des)conectada: usos das mídias e consumos culturais de professores. Anais da 33a Reunião Anual da ANPED. Caxambu, 2010b.

GATTI, B.; BARRETO, E. S. Professores do Brasil: impasses e desafios. Brasilia: Unesco, 2009.

GRANATA, P. Arte, estetica e nuovi media: sei lezioni sul mondo digitale. Bologna: Fausto Lupetti, 2009.

HOBBS, R. Multiple Vision of Multimedia Literacy: Emerging Areas of Sinthesis. 2006. Disponível em: http://reneehobbs.org/renee's\%20web\%20site/publications/ Hobbs\%20final\%20PDF\%20Literacy\%20and\%20Technology\%20Vol\%202.pdf Acesso em: 17 dez. 2007.

JENKINS, $\mathrm{H}$. Confronting the chalenges of Participatory Culture: Media Education for the 21st Century. Chicago: MacArthur Foundation, 2006.

Cultura da convergência. 2. ed. São Paulo: Aleph, 2009.

LEITE, M. I.; GUIMARAES, D.; NUNES, M. F. História, cultura e expressão: fundamentos na formação do professor. In: KRAMER, S.; LEITE, M. I.; GUIMARAES, D.; NUNES, M. F. Infância e educação infantil. 2. ed. Campinas: Papirus, 1999.

MACHADO, A. Arte-mídia. Rio de Janeiro: Jorge Zahar, 2007.

MARTÍN- BARBERO, J. Dos meios às mediações. 2. ed. Rio de Janeiro, Editora UFRJ, 2001.

MASSEY, D. Pelo espaço: uma nova política da espacialidade. Rio de Janeiro: Bertrand Brasil, 2008.

MAYER, R. Multimedia Learning. Cambridge: Cambridge University Press, 2001.

MIDORO, V. et al. Le ICT nella pratica e nello sviluppo professionale dei docenti. TD, 3, p. 18-24, 2003.

NOGUEIRA, M. A. Experiências estéticas em sala de aula: possibilidades na formação cultural de futuros professores. In: Anais da 31를 Reunião Anual da ANPED, 2008. Disponível em http://www.anped.org.br/reunioes/31 ra/1trabalho/ GE01-4022-Int.pdf. Acesso em: 26 mar. 2012. 
NÓVOA, A. Formação de professores e profissao docente. In: NÓVOA, A.(Org.).Os professores e sua formação. Lisboa: Dom Quixote, 1995.

PRETTO, N.; RICCIO, N. A formação continuada de professores universitários e as tecnologias digitais. Educar, n. 37, p. 153-169, maio/ago. 2010. Disponível em: http://www.scielo.br/pdf/er/n37/a10n37.pdf. Acesso em 26 mar. 2012.

RIVOLTELLA, P. C. Formar a competência midiática. Revista Comunicar, n. $25,2005$.

. (Ed). Digital Literacy. Tools and Methodologies for Information Society. New York: IGI Publishing, 2008.

Rappresentare. Conoscenza, media, tecnologia. In CATTANEO, A.; RIVOLTELLA, P. C. Tecnologie, formazione, profissione. Milano: Unicopli, 2010, p. 39-60.

SANTAELLA, L. Por que as comunicações e as artes estão convergindo? São Paulo: Paulus, 2005.

SEVERINO, A. J. A formação e a prática do professor em face da crise atual dos paradigmas educacionais. Ciencia \& Opinião, v. 1, n. 2/4, jul. 2003/dez. 2004, p. 15-31.

SILVERSTONE, R. Mediapolis. La responsabilità dei media nella civiltà globale. Milano: Vita\&Pensiero, 2009.

UNESCO. O perfil dos professores brasileiros: o que fazem, o que pensam, o que almejam. Pesquisa Nacional Unesco. São Paulo: Moderna, 2004.

Padrões de competência em TIC para professores. Diretrizes de implementação. Brasília: Unesco, 2008.

ZEICHNER, K. Uma agenda de pesquisa para a formação docente. Revista Brasileira de Pesquisa sobre a Formação Docente, v. 1, n. 01, p.13-40, ago./dez. 2009.

\section{Correspondência}

Monica Fantin - Universidade Federal de Santa Catarina, Departamento de Metodologia do Ensino, Campus Universitário, Trindade, CEP 88040-900 - Florianópolis, Santa Catarina.

E-mail:mfantin@terra.com.br

Recebido em 03 de fevereiro de 2012

Aprovado em 04 de março de 2012 